\title{
Design and Construction of Test Coils for the MICE Coupling Solenoid Magnet
}

\author{
L.Wang, H.Pan, F.Y.Xu, X.K.Liu, A.B.Chen, L.K.Li, X.L.Guo, H.Wu, \\ M. A. Green Member IEEE, D. R. Li, and B. P. Strauss Sr. Member IEEE
}

\begin{abstract}
The superconducting coupling solenoid to be applied in the Muon Ionization Cooling Experiment (MICE) is made from copper matrix $\mathrm{Nb}$ - Ti conductors with inner radius of $750 \mathrm{~mm}$, length of $285 \mathrm{~mm}$ and thickness of $102.5 \mathrm{~mm}$ at room temperature. The magnetic field up to $2.6 \mathrm{~T}$ at the magnet centerline is to keep the muons within the MICE RF cavities. Its self inductance is around $592 \mathrm{H}$ and its magnet stored energy is about $13 \mathrm{MJ}$ at a full current of 210 A for the worst operation case of the MICE channel. The stress induced inside the coil during cool down and charging is relatively high. Two test coils are to build and test in order to validate the design method and develop the fabrication technique required for the coupling coil winding, one is $350 \mathrm{~mm}$ inner diameter and full length same as the coupling coil, and the other is one-quarter length and $1.5 \mathrm{~m}$ diameter. The $1.5 \mathrm{~m}$ diameter coil will be charged to strain conditions that are greater than would be encountered in the coupling coil. This paper presents detailed design of the test coils as well as developed winding skills. The analyses on stress in coil assemblies, AC loss, and quench process are carried out.
\end{abstract}

Index Terms-MICE magnet, stress, AC losses, quench, winding system, cool down test

\section{INTRODUCTION}

$\mathrm{T}$ HE international Muon Ionization Cooling Experiment (MICE) will be a demonstration of muon cooling in a configuration of superconducting solenoid magnets and absorbers that may be useful for a future neutrino factory [1]. A pair of coupling magnets is applied to produce up to $2.6 \mathrm{~T}$ on the magnet centerline to keep the muon beam within the thin RF cavity windows. The peak field of the coupling coil is up to $7.4 \mathrm{~T}$ at the worst case and the operation temperature margin of the magnet is only about $0.8 \mathrm{~K}$ [2].

Because of high magnetic field and large size of the coupling magnet, the stress inside it is relatively high during cool down and full charging. When applying winding prestresses of $70 \mathrm{MPa}$ on the coil, the hoop stress at the outmost layer of coupling coil is in tension about $103 \mathrm{MPa}$ after

Manuscript received 19 August 2008. This work was supported by Funds of cryogenics and superconductivity technology innovation project under "985-2 Plan" of Harbin Institute of Technology. This work was also supported by the Office of Science, US Department of Energy under DOE contract DEAC02-05CH11231. DOE funding of the US Neutrino Factory Muon Collider Collaboration is greatly appreciated.

L. Wang, H. Pan, F. Y. Xu, et al. are with the Institute of Cryogenics and Superconductive Technology, Harbin. Institute of Technology, Harbin 150001, China (e-mail: WangLi icst@hit.edu.cn). M. A. Green and D. R. Li are with Lawrence Berkeley National Laboratory, Berkeley, CA, 94720 USA (e-mail: magreen@lbl.gov). B. P Strauss is from the Office of Science, US Department of Energy, Germantown MD, USA charged to full current of $210 \mathrm{~A}$, and the peak Von Mises stress is about $151 \mathrm{MPa}$ which appears at the centre of the outmost layer.

Two test coils were designed and under constructing in order to validate the magnet design method and develop the fabrication technique for coil winding. The two test coils adopted the copper matrix $\mathrm{NbTi}$ conductors with the cross area of $1.65 \times 1.00 \mathrm{~mm}^{2}$, which is same as the MICE coupling magnet. The small test coil is $350 \mathrm{~mm}$ inner diameter with full length of $285 \mathrm{~mm}$ as the coupling coil but only 20 layers; the large test coil is $1.5 \mathrm{~m}$ inner diameter with one-quarter length of the coupling coil and the same layers of 96 as coupling coil. All the skills to be used for fabricating the coupling coil will be performed on the two test coils.

\section{Design For TeSt CoILS}

The small coil is to be used for testing and debugging the winding machine and the soldering skills for conductor splices while winding. The large coil is to be used for simulating the stress and strain conditions that would be encountered in the coupling coil [3]. The material of the two test coils' mandrel and cover plate is 6061-T6 aluminum alloy, and the banding is made from 316 stainless steel wire.

When the coupling coil at the worst case which is charged at $210 \mathrm{~A}$, the operation temperature margin is about $0.8 \mathrm{~K}$, according to the load line shown in Fig. 1. For small coil and the large coil, in order to fulfill the objective to simulate the stress situation, and with the same temperature margin, the highest current is about $500 \mathrm{~A}$ and $350 \mathrm{~A}$ respectively. The basic parameters for two test coils are listed in Table I and the schematic of their cross sections are in Fig. 2.

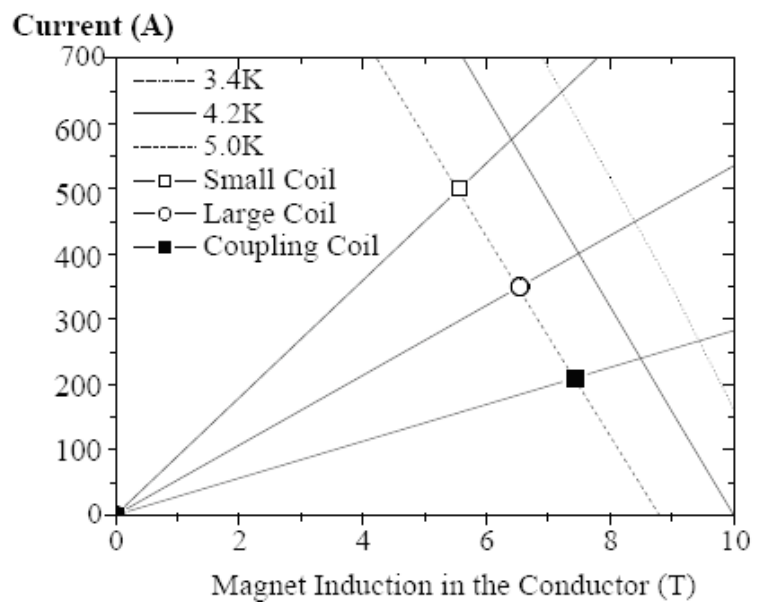

Fig. 1. The load line for small coil, large coil and coupling coil 
TABLE I THE BASIC PARAMETERS

\begin{tabular}{ccc}
\hline \hline Parameters & $\begin{array}{c}\text { Small } \\
\text { Coil }\end{array}$ & $\begin{array}{c}\text { Large } \\
\text { Coil }\end{array}$ \\
\hline Coil Length (mm) & 285 & 72 \\
Coil Inner Radius (mm) & 175 & 750 \\
Coil Thickness (mm) & 25.5 & 102.5 \\
Number of Layers & 20 & 96 \\
No. Turns per Layer & 166 & 42 \\
Magnet J (A mm-2) & 95.9 & 114.6 \\
Magnet Self Inductance (H) & 3.14 & 50.8 \\
Peak Induction in Coil (T) & 2.33 & 3.93 \\
\hline \hline
\end{tabular}

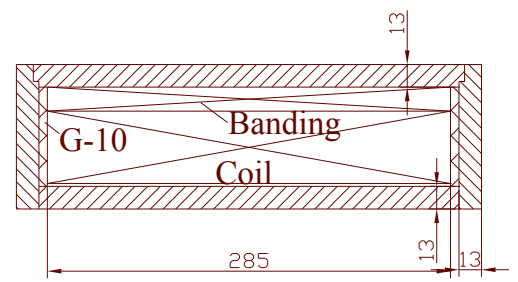

Fig. 2a Small coil

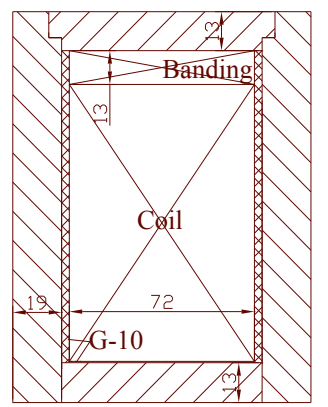

Fig. 2b Large coil

\section{A. The analyses on stresses in the two coil assemblies}

The FEA model used for stress simulation during the processes of coil winding, cool down and full charging includes the coil, mandrel, banding, G-10 insulations and cover plate as shown in Fig. 2. The winding pre-stress on the conductor is set as $70 \mathrm{MPa}$ and $60 \mathrm{MPa}$ on the banding.

Table II shows the simulation results for the coils. For the large coil, after winding the coil onto the mandrel, the tensile hoop stress at its outmost layer is about 55.9 $\mathrm{MPa}$, which is close to the pre-stress of $70 \mathrm{MPa}$ impacting on the conductor by divided by fill factor 0.78 . So the numerical result is in agreement with actual winding process. During cool down from $300 \mathrm{~K}$ to $4.2 \mathrm{~K}$, the peak compressive stress is $\sim 107 \mathrm{MPa}$ in the inner center of the coil. The tensile stress on the outmost layer is about $22 \mathrm{MPa}$. After charged to full current, the peak tensile hoop stress is about $80 \mathrm{MPa}$ on the outmost layer. The compressive hoop stress in the inner central surface is almost zero. The peak von Mises stress is about $131 \mathrm{MPa}$, which appears at the centre of the outmost layer. Because of the bobbin of the coupling coil is longer than that of larger coil, so the von Mises stress of the coupling coil is a little higher than the large coil during winding.

TABLE II STRESSES IN THREE COILS

\begin{tabular}{cccccccccc}
\hline \hline $\begin{array}{c}\text { Parameter } \\
\text { (MPa) }\end{array}$ & \multicolumn{3}{c}{ Pre-winding } & \multicolumn{3}{c}{ Cooling } & \multicolumn{4}{c}{ Charging } \\
& $\mathbf{S}^{*}$ & $\mathbf{L} *$ & $\mathbf{C} *$ & $\mathbf{S}$ & $\mathbf{L}$ & $\mathbf{C}$ & $\mathbf{S}$ & $\mathbf{L}$ & $\mathbf{C}$ \\
\hline $\begin{array}{c}\text { Hoop ** } \\
\text { Radial }\end{array}$ & 54.7 & 55.9 & 54.2 & 20 & 22 & 46 & 50 & 80 & 103 \\
$* *$ \\
Max.
\end{tabular}

${ }^{*} \mathrm{~S}$ is small coil, $\mathrm{L}$ is large coil and $\mathrm{C}$ is the coupling coil, ** Hoop stress is the value on the outermost layer; Radial stress is the value in the inner layer.
From Table II, it appears that the maximum stresses in the large coil at $350 \mathrm{~A}$ are close to the maximum stress for the coupling coil. If the large test coil can be operated at or near the $4.2 \mathrm{~K}$ short sample current, the peak stresses in the large coil will be higher than the design stresses for the MICE coupling magnet at its maximum current.

\section{B. AC losses in test coils}

In order to calculate hysteretic AC loss more accurately, the cross-sections of two test coils were divided into five regions and the charging process was divided into four time steps, and the results were summarized in Table III and Table IV [4].

TABLE III AC LOSSES IN SMALL COIL

\begin{tabular}{cccc}
\hline \hline Time (s) & Hysteretic Loss (W) & Mandrel Loss(W) & AC loss (W) \\
\hline 450 & 0.0947 & 0.0025 & 0.0972 \\
1350 & 0.0691 & 0.0025 & 0.0716 \\
2250 & 0.0523 & 0.0025 & 0.0548 \\
3150 & 0.0415 & 0.0025 & 0.0440 \\
\hline \hline
\end{tabular}

TABLE IV AC LOSSES IN LARGE COIL

\begin{tabular}{cccc}
\hline \hline Time (s) & Hysteretic Loss (W) & Mandrel Loss(W) & AC loss (W) \\
\hline 450 & 1.378 & 0.056 & 1.434 \\
1350 & 0.770 & 0.056 & 0.826 \\
2250 & 0.497 & 0.056 & 0.553 \\
3150 & 0.374 & 0.056 & 0.43 \\
\hline \hline
\end{tabular}

Both test coils will be cooled by liquid helium in cooling tubing by means of thermo-siphon principle. Compared with the available cooling capacity, the AC losses are negligible.

\section{Quench process in test coils}

The quench protection for test coils is designed as the passive protection. The technology of subdivision and quenchback is adopted in order to reduce the inner voltage and the hot-spot temperature [5][6][7]. The quench protection of the small coil is subdivided into two subsection using $0 \Omega$ resistors; the large coil is subdivided into four sections as shown in Fig. 3. Each subsection consists of a pair of back to back diodes and a resistor. The simulation results of quench process for the two coils are listed in the Table V. The peak internal voltage is less than the allowable breakdown voltage of electrical insulation between layers.

TABLE V Simulation Results OF QUENCH PROCESS

\begin{tabular}{ccc}
\hline \hline Parameters & Small Coil & $\begin{array}{c}\text { Large } \\
\text { Coil }\end{array}$ \\
\hline The hot spot temperature $(\mathrm{K})$ & 113 & 117 \\
The peak internal voltage(V) & 885 & 1973 \\
\hline \hline
\end{tabular}




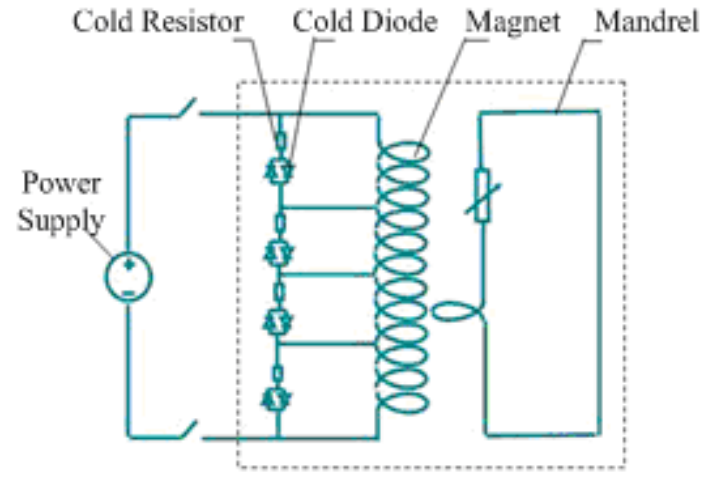

Fig.3. The quench protection scheme for large coil

\section{WINDING SKILLS FOR TEST COILS}

\section{A. Winding System}

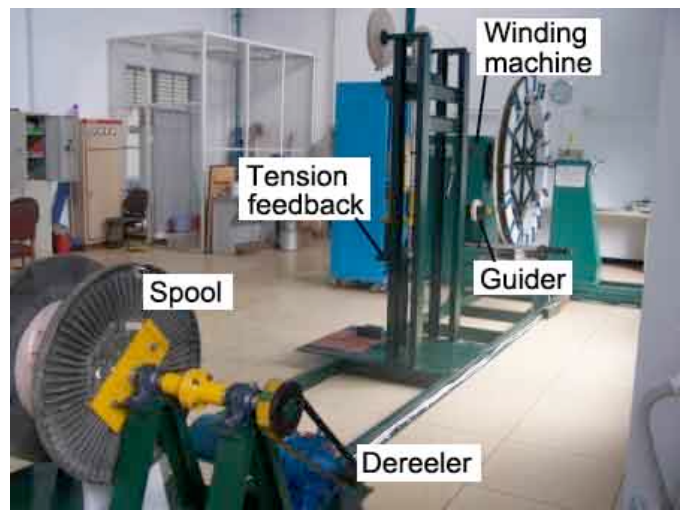

Fig. 4. The layout of solenoid magnet winding machine

A set of winding system for the solenoid magnet was built in ICST as shown in Fig. 4. The winding system mechanically consists of a winding machine, an automatic guider, a tension adjusting mechanism, and a dereeler (a facility that unwinds conductor from the spool) [3]. The developed technology for the winding machine includes; variable winding speed, high accuracy wire alignment, and constant tension control. The ICST winding facility has capabilities of winding small and medium sized solenoid coils. The automatic guider can provides turn-to-turn stepping distance of $1.717 \mathrm{~mm}$ per turn of the main shaft during the winding of the coupling coil. The designed tension range for the winding machine will be of $50 \sim 350 \mathrm{~N}$, because tension adjusting mechanism depends on the set of movement masses. The dereeler will work along with the tension adjusting mechanism to provide constant tension control for the coil winding or unwinding. The function modules such as automatic guider and tension adjusting mechanism are movable and the relative position of the modules will depend on the coil size to be wound.

\section{B. Small Coil Winding}

Electrical insulations must be applied between the coil to ground or mandrel, between coil layers, and between the coil and banding. For ground insulations, two layers of G-10 sheets with $0.5 \mathrm{~mm}$ of thickness each were wrapped onto the cylindrical 6061-aluminum mandrel with Stycast epoxy. The coil end insulation consists of two G-10 plates with a total thickness of $3 \mathrm{~mm}$ that were glued onto end plates of the coil mandrel. The coil to mandrel insulation should pass $5 \mathrm{kV}$ hipot test and the leak current should be less than $50 \mathrm{~A}$.

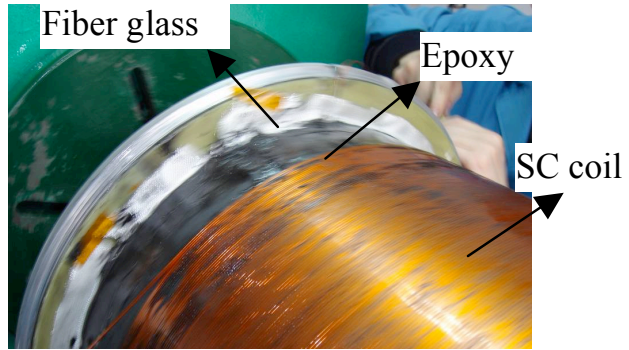

Fig. 5 Winding of small coil

The insulations between layers are composed of fiberglass cloth and epoxy as shown in Fig. 5. Once the first layer is wound, the fiberglass cloth with $0.1 \mathrm{~mm}$ of thickness is wrapped over it, and then to brush the epoxy and winding the conductor for the next layer. The thickness per layer is controlled within $1.24 \mathrm{~mm}$ and should be evenly.

Banding with pre-tension winding on the coil will provide some hoop force support and ensure the coil is tightly packed when it is cooled down. The brass wire of $1.7 \mathrm{~mm}$ in diameter was used to band the coil, and the starting end and the tail end were connected together by soldering in order to maintain the tension.

According to the FEA simulation, the pre-stress of $70 \mathrm{MPa}$ is applied for both test coils during winding. The pre-tension applied on the coil banding is $60 \mathrm{MPa}$, and the actual thickness of the banding for the small coil is $7 \mathrm{~mm}$ with 4 layers of brass wires. The coil will be further insulated by two layers of $0.5 \mathrm{~mm}$ thick G-10 sheets with epoxy before banding. Two layers of Kapton film with a thickness of 0.02 $\mathrm{mm}$ were glued into the corners of mandrel end plates and outside the G-10 insulation system in order to enhance the electrical insulation in those regions.

\section{Superconducting Joints}

In the small test coil, there are two superconducting joints. The large coil may have 5 to 6 splices (also referred to as joints). The full MICE and MuCOOL coupling coils may have as many as a dozen splices within the coil.

Two types of overlap soft solder lap joints have been studied and made by ICST for the MICE coupling coils and test coils, which are the up-down lap joints and the side-byside joints. The up-down lap joints can only be placed at the ends of the coil, so there will be no turns lost in one coil layer. The side-by-side joints can be made in the middle of the layer in magnet coils, so less conductor will be thrown away in the winding process. Two kinds of low melting point soft solder, $\mathrm{Sn}_{63} \mathrm{~Pb}_{37}$ and $\mathrm{Ag}_{3.5} \mathrm{Sn}_{96} \mathrm{Cu}_{0.5}$, were tested for each joint type as well. The overlap length of all splices is about $1 \mathrm{~m}$. The effects of the solder and the magnetic field on the splice resistance were tested in LBNL as shown in Table VII and Fig. 6. Measurements were done on a center section of $0.25 \mathrm{~m}$ long as well as the full splice length. The results normalized to a splice length of 1-meter [8].

The splice resistance of side-by-side joints is not very different from the resistance of up-down joints and the normalized resistances of both types of joints are in the range of $0.7 \mathrm{n} \Omega$ to $1.7 \mathrm{n} \Omega$. The resistance does not appear to increase rapidly with magnet fields. The data in Fig. 6 and 
Table VI suggests that the resistance of the $\mathrm{Ag}_{3.5} \mathrm{Sn}_{96} \mathrm{Cu}_{0.5}$ joints may be lower than for the $\mathrm{Sn}_{63} \mathrm{~Pb}_{37}$ joints, but the difference between the two solders seems more pronounced for the side-by-side joint. The selection of the solder for the joint should be based on other factors such as strength and susceptibility to tin rot at low temperatures, which will be further studied later.

TABLE VI NoRMALIZED SPlice RESISTANCE AT B=1T

\begin{tabular}{cccc}
\hline \hline Splice Type & Type of Solder & $\begin{array}{c}\text { Splice } \\
\text { Length }\end{array}$ & $\begin{array}{c}\text { Normalized } \\
\text { Resistance(n_) }\end{array}$ \\
\hline Up-down & $\mathrm{Ag}_{3.5} \mathrm{Sn}_{96} \mathrm{Cu}_{0.5}$ & $1.02 \mathrm{~m}$ & 1.08 \\
Side-by-side & $\mathrm{Ag}_{3.5} \mathrm{Sn}_{96} \mathrm{Cu}_{0.5}$ & $1.00 \mathrm{~m}$ & 1.17 \\
Up-down & $\mathrm{Sn}_{63} \mathrm{~Pb}_{37}$ & $1.04 \mathrm{~m}$ & 1.25 \\
Side-by-side & $\mathrm{Sn}_{63} \mathrm{~Pb}_{37}$ & $1.00 \mathrm{~m}$ & 1.54 \\
\hline \hline
\end{tabular}

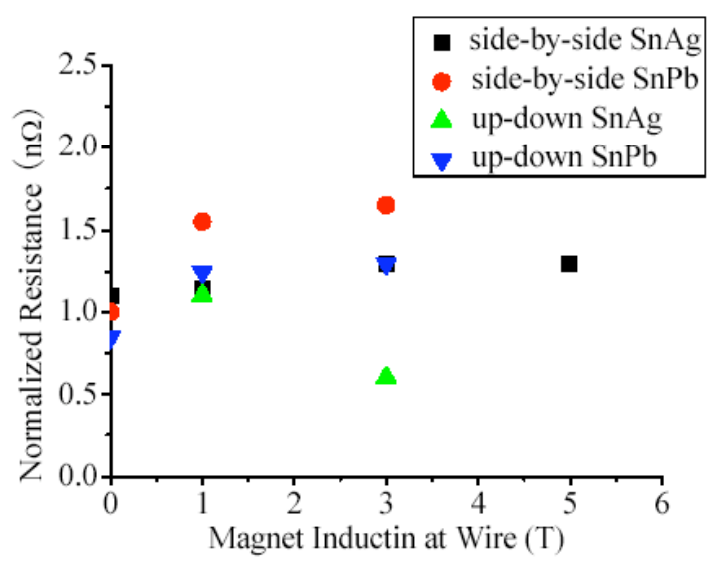

Fig. 6 Two types of splice resistance as a function of magnetic induction for the length of $1.0 \mathrm{~m}$

\section{The $\mathrm{LN}_{2}$ CoOl Down Results of SMall CoIL}

The LN2 cool down test is executed after winding the small coil to test the uniformity of temperature in the coil during cool down, the electricity performance, and the ability of enduring to thermal stress. The mainly facilities consists of a 500 L LN2 dewar, a test cryostat, cooling pipelines, mechanical and turbo molecular pump group, and regulating valves. During the cool down of the coil, the maximum difference of temperature on the coil was controlled no higher than $30 \mathrm{~K}$ and the cool down speed was less than $30 \mathrm{~K} /$ hour to protect the coil from thermal crack. The vacuum of cryostat is kept at $1.6 \times 10^{-2} \mathrm{~Pa}$ during cooling down, and from room temperature to $77 \mathrm{~K}$, and it took about 4 hours.

The measured resistance of the small coil is fit well with the calculation at low temperature as shown in Fig. 7. The difference of measured results and calculation results near room temperature is about $5 \mathrm{ohms}$. This may be because the actual length of the conductor in the coil is longer than the length was calculated.

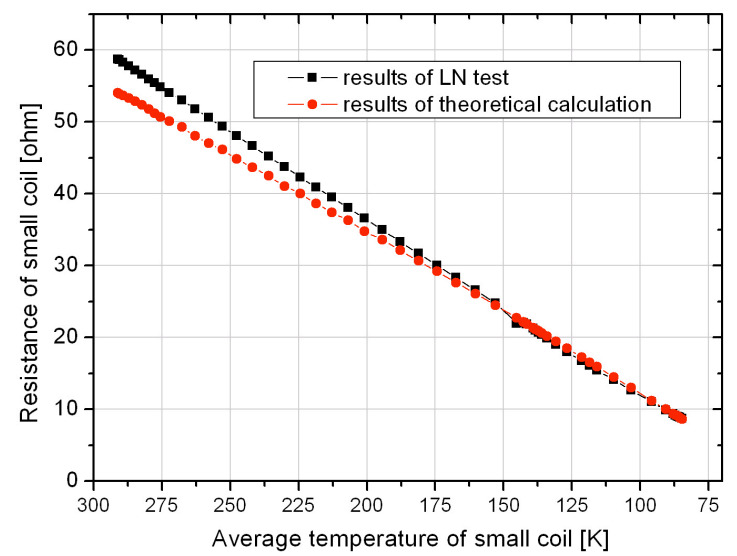

Fig.7. The resistance of small coil during cooling down

The cryogenic test facility for the test coils and MICE coupling coils was still under construction in ICST at the time this report was written. Once the cryogenic system is built, the electrical and cryogenic performance of the two test coils will be measures. The results of these tests will be reported on, in future report.

\section{CONCLUSION}

The design work for two test coils were carried out for the MICE coupling magnet system. The small coil was fabricated and cooled to liquid nitrogen temperature by ICST. Tests at helium temperature will occur when the cryogenic test system construction is finished. The large test coil is under construction at ICST. The design method for the coupling magnets will be validated by the test coils. The skills needed for fabricating the coupling coil will also be validated on the small and large test coils before the report is published.

\section{REFERENCES}

[1] G. Gregoire, G. Ryckewaert, L. Chevalier, et al, "MICE and International Muon Ionization Cooling Experiment Technical Reference Document", [on line] http://hep04.phys.itt.edu/cooldemo.

[2] L. Wang, M. A. Green, F. Y. Xu, et al, "The Engineering Design of the $1.5 \mathrm{~m}$ Diameter Solenoid for the MICE RFCC Modules", IEEE Transactions on Applied Superconductivity 18, No. 2 p 937-940 (2008).

[3] Institute of Cryogenics and Superconductivity Technology, "Engineering Design of MICE/MUCOOL Coupling Solenoid Magnet", Harbin Institute of Technology, CHINA (2007).

[4] Green, M. A., Wu, H., Wang, L., L., L. Kai, Jia, L. X. Yang, S. Q., "AC Losses in the MICE Channel Magnets Is This a Curse of a Blessing?", LBNL-63804 and MICE Note-195, (2008).

[5] M. A. Green and H. Witte, "Quench Protection and Power Supply Requirements for the MICE Focusing and Coupling Magnets," LBNL57580, 8 May 2005.

[6] M. A. Green, L. Wang, X. L. Guo, et al "Quench Protection for the MICE Cooling Channel Coupling Magnet". LBNL-63698, 31 January 2008.

[7] X. L. Guo, F.Y. Xu, L. Wang, M. A. Green, et al "Quench Protection for the MICE Cooling Channel Coupling Magnet," submitted to IEEE Transactions on Applied Superconductivity 19, August 2008.

[8] Michael A. Green, Dan Dietderich, Hugh C. Higley, et al, "The Calculated and Measured Resistance for Joints between Conductors in a MICE Superconducting Coil”, MICE Note (July 2008), to be published. 
This document was prepared as an account of work sponsored by the United States Government. While this document is believed to contain correct information, neither the United States Government nor any agency thereof, nor The Regents of the University of California, nor any of their employees, makes any warranty, express or implied, or assumes any legal responsibility for the accuracy, completeness, or usefulness of any information, apparatus, product, or process disclosed, or represents that its use would not infringe privately owned rights. Reference herein to any specific commercial product, process, or service by its trade name, trademark, manufacturer, or otherwise, does not necessarily constitute or imply its endorsement, recommendation, or favoring by the United States Government or any agency thereof, or The Regents of the University of California. The views and opinions of authors expressed herein do not necessarily state or reflect those of the United States Government or any agency thereof, or The Regents of the University of California. 